DOI $10.37882 / 2500-3682.2020 .05 .11$

\title{
МЕНТАЛЬНЫЕ ОСНОВАНИЯ ТВОРЧЕСТВА
}

\section{MENTAL FOUNDATIONS OF CREATIVITY \\ A. Nekrasov}

Summary: The purpose of the article is to analyze the significance of mentality as the foundation of a national character in the realization of the creative potential of man and society. The article discusses such components of the mentality as archetypes, the national idea, the soul of the people, natural factors, the genetic foundation, the mental code, each of which carries its own functional load, and the mentality as a multi-level phenomenon manifests itself on the virtual and essential levels.

Keywords: mentality, archetypes, ethnopsychology, national idea, national-ethnic community, soul of the people, natural factors, image, mental code.

\author{
Некрасов Андрей Сергеевич \\ К.п.н., доцент, Российский университет транспорта \\ sinekrasov@mail.ru
}

Аннотация: Целью статьи является анализ значения ментальности как фундамента национального характера в реализации творческого потенциала человека и общества. В статье рассматриваются такие составляющие менталитета как архетипы, национальная идея, душа народа, природные факторы, генетический фонд, ментальный код, каждое из которых несёт свою функциональную нагрузку, а менталитет как многоуровневый феномен проявляется на виртуальном и эссенциальном уровнях.

Ключевые слова: менталитет, архетипы, этнопсихология, национальная идея, национально-этническое сообщество, душа народа, природные факторы, образ, ментальный код, национальный характер. онятие менталитета исследованиями интерпретируются по-разному. Анализ многочисленных его определений даёт основание выделить в них три подхода: как «образ мышления народа» (рационалистическое направление), как «психический склад», «национальная психоструктура» (психологическое направление), как мировоззренческие проявления духовной жизни народа, матрица мировосприятия и миропонимания (комплексное направление).

Ментальными характеристиками обладают народы, эпохи, индивиды как представители этнических общностей, которые представляют собой исторические ценности довольно длительное время, накапливая определённые черты, проявляющиеся в их внутреннем субъективном мире и поведении.

Являясь проявлением исторической целостности, менталитет любого этноса постепенно проходит следующие стадии: становление психологических архетипов как фундамента характеристик этноса, сохранение закреплённого проявления психики и поведения этнической общности в языковой, культурной и нравственной форме при наличии некоторых их модификаций; формирование этнического самосознания и закрепление его на уровне подсознания (в виде «души народа» и «национального характера») или рационально-осознанных идей («русская идея»).

Конкретному человеку ментальность этноса и эпохи даётся генетически в виде целой структуры этнопсихологических задатков, которые в культурно-исторической среде развёртываются, проявляясь в его поведе- нии и деятельности. Менталитет по своему содержанию на уровне индивида выступает феномен психики и поведения и проявляется в виде эмоций, установок, автоматизму реакций и поведения, иначе его можно определить как этнокультурный код, который зафиксирован в национальном языке, традициях, фольклоре и т.п.

Если понятия духовность и мировоззрение отражают проявления человеческого духа (хотя каждое из них имеет разную природу и несут реальный смысл), то менталитет является специфической формой духовности, несущей национально-этническую особенность.

Духовность - это сфера проявления идеального во всех его проявлениях или высшая форма человеческого бытия, имеющая три уровня - виртуальный, эссенциальный и трансцендентальный, которые выражаются в подсознательных, сознательных, сверхсознательных (психологических и интеллектуальных) субъективных образованиях.

Мировоззрение - это целостный, системный взгляд человека на мир, который регулирует его отношения в виду философско-рационального мышления и иррациональных проявлений его деятельности. Другими словами, мировоззрение - это «застывшая духовность», это обобщённый дух эпохи. И если мировоззрение - застывшая духовность, то менталитет - это первично глубинное основание духовности (его виртуальное начало), т.к. оно основано на психических и культурных архетипах, которые на подсознательном уровне спонтанно-непосредственно регулируют действия человека как представителя этнической общности. Если мировоззрение 
рационально, то менталитет - это внерациональные образования, где закрепляются и вербализуются стереотипы бытия национально-этнических сообществ.

Философский смысл духовности состоит в её интегрирующем назначении объединять разделённые во времени и пространстве культурные достижения этноса, концентрируя их в человеческих проявлениях и в определённых типах духовности [10]. Мировоззрение как философская категория, отражающая рациональную дифференциацию человечества на общности, а философский смысл понятия менталитет заключается в закреплении генетически обусловленных стереотипов бытия человека как представителя этнической общности (что отождествляет его с общностью) и проявляется в его поведении. Менталитет - феномен жизни народа, это форма национально-этнической дифференциации в обществе, которая отражает специфику этнических, материальных и духовных, культурно-деятельностных проявлений, а также отношения этнических общностей к людям, к миру, к природе, к другим народам и к самому себе.

Менталитет как духовное явление имеет многоуровневый характер. Составляющими менталитета являются: психический склад народа (нации), национальный характер, национальное самосознание, которые проявляются на виртуальном и эссенциальном уровнях.

Одна из характеристик менталитета - понятие «душа народа» как проявление национального характера в его стереотипах поведения и типических реакциях. Как отмечал Н. Бердяев, это «неуловимый остаток», в котором скрыта «тайна национальной индивидуальности». Душа народа - это динамика типических проявлений в повседневной жизни этноса и каждого человека. Одной из его характерных черт является антиномичность, которая предполагает, что нет абсолютно положительных или отрицательных национальных ментальных общностей. Это скорее единство противоположностей, которые в определённых ситуациях проявляется тем или иным образом [2].

Как утверждал Н.О. Лосский, противоположности есть у всех народов, но они проявляются у каждого народа своеобразно и важно увидеть, какие из них первичны, а какие производны [7;8].

Основой менталитета, по мнению автора статьи, выступают философское мировоззрение (или религиозное верование), народные знания (обычаи, традиции, обряды, устное народное творчество, народное искусство) и другие духовные явления в их национально-этническом оформлении. А в явлениях материальной культуры народа - это национальные формы хозяйственной деятельности, условия быта, характер поселения, народная архитектура, одежда, питание и др. Связующим звеном между материальной и духовной культурой этноса выступают семейные отношения, гражданский быт и политические традиции. Универсальным оформлением менталитета является язык как средство хранения и развития национального самосознания и духовности.

Ментальность этноса и человека тесно взаимосвязаны. Национальное самосознание - это внешняя сторона менталитета человека, рационально им осмысленная и вербально оформленная. Самосознание этнической общности проявляется как система концептуальных философских, культурологических, исторических позиций, в которых отражается исторический путь народа, его места среди других народов и пути будущего развития.

Центральное место в национальном самосознании занимает национальная идея, которая наиболее полно отражает мироощущение и мировосприятие народа. Первой попыткой изложения «русской идеи» была концепция «Москва - третий Рим», которую в послании царю Василию III сформулировал монах псковского монастыря Филофей. Согласно этой концепции, Москва (т.е. Русь) должна после двух столиц мировых империй (Рима и Константинополя) взять на себя духовную миссию, т.е. вывести человечество на светлый путь, опираясь на духовно-нравственные основы христианства [1]. Вся русская религиозная философия будущих времён пыталась выполнить эту миссию - показать пути выхода человечества к эпохе Богочеловечества.

В основе национальной идеи на уровне индивида лежит самосознание, которое представляет собой осознание им своей принадлежности к этнической общности (т.е. эмоциональное, ценностно-ориентированное и рациональное отношение к нему). Индивидуальное национальное самосознание выражается в знаниях, эмоциональных оценках явлений, в типических чертах характера и др. Национальное самосознание проявляется в чувстве национального достоинства в памяти о предках, в привычных эмоциональных формах мышления.

Ментальным кодом социально-значимой информации является образ, который переживается человеком в качестве находящегося вне его психики предмета материального мира. Объясняя это свойство образа, А.Н. Моисеев писал: «В образе нам даны не наши субъективные состояния, а сами объекты» [6, с. 44]. Для субъекта образ как бы наложен на вещь. Образ - это копия объекта или возникающее в психике изображение объекта. Образ это форма визуального выражения информации о предмете, переживаемая человеком в качестве реально существующего объекта.

Образ, являясь способом восприятия мира в обыденном коллективном сознании, выступает закодирован- 
ной сущностно-значимой для человека информацией. Он формируется при помощи множества социальных механизмов: общественного мнения, национальных традиций, архетипных стереотипов, идеологических ориентаций и др.

Благодаря выразительной силе образы «правят обществом, придают людям «правильный» образ действий, задают стандарты поведения, соответствующие принятым в данном социуме культурным установкам.

Будучи высокоорганизованными ментальными структурами, образы не только отражают социальное бытие, но одновременно запечатлевают его в качестве кодов значимой для этноса информации.

Образы раскрывают социальную направленность моделируемой социокультурной парадигмы уже на ранней стадии её становления, поэтому выполняют предпосылочную функцию.

Образ, как руководящая идея (императив) представляет собой идеальную форму, которая превращается в установку социокультурного мышления и средства рационального осмысления социальных проблем.

Образ - идеал, образец, особая мыслительная (ментальная) модель, включающая в себя комплекс представлений общественного сознания о наиболее желаемых, предпочтительных формах социальной жизни. Образ - это цель, выступающая в виде мысленного предвосхищения идеально желаемого результата или предназначения любого вида человеческой деятельности.

Теоретический анализ особенностей менталитета необходим для определения путей дальнейшего развития общества, то есть, каким образом можно использовать духовные национально-этнические ресурсы народа и реализацию творческого потенциала общества и каждого его представителя [4].

Творческий потенциал общества определяется, прежде всего, существующим генетическим фондом населения, физическим здоровьем и его умственными задатками, а также социальными условиями для реализации интеллектуальных и профессиональных возможностей населения.

Если говорить о мировоззренческих особенностях российского народа, то в нём специфически срослись дохристианские, языческие и мифологические представления с обрядностью византийского христианства. Господство восточного православия на протяжении тысячелетия легло основу формирования ментальных особенностей русского народа. Сюда можно отнести терпимость, выносливость, добродушие, широту души, умение концентрировать все свои силы для реализации цели, стремление к новации в быту и творчестве, а также вера в «отца» народа и его политику, что становилось идейной основой для формирования тотальных режимов.

Культура как сущностная основа менталитета охватывает как творческие, так и нетворческие моменты. Вступая во взаимодействие с ментальными особенностями, культура участвует в трансформировании витальных задатков этноменталитета в процессы культивирования, закрепляя их в определённом типе культуры.

Творческая роль культуры во взаимодействии с менталитетом проявляется в том, что она способствует осознанию глубинных ментальных особенностей и оформлению их в виде благоприятных для распространения и усвоения феноменов культуры. Через культуру ментальные установки осознаются, корректируются и становятся частью народной души. Культура как основа человеческой жизнедеятельности становится её творческим компонентом по корректировке содержания ментальности, связывая старое и новое, традиции и современность, наследие и утопии.

Отличие направленности творчества на создание вещей внешнего мира в западноевропейской культуре от особенностей творческого потенциала русского народа, направленного в сторону развития внутреннего духовного мира, проявляясь в самоуглублённости, самопостижимости субъекта творчества. Отсюда индивидуализм русского человека коренным образом отличается от индивидуализма западного европейца большими проявлениями самостоятельной ответственности, инициативности. Причём, в менталитете русского народа общественное превалирует над личным, коллективное над индивидуальным, развитию «вширь»- развитие индивида «вглубь.

В концентрированном виде черты русского национального характера, сфокусированные в менталитете, выделяют женское начало, отодвигая мужское. Иначе, русский характер непредсказуем как женщина, а его духовные качества представляют собой национальные формы воплощения творческого потенциала человека и общества.

Природный фактор играет большую роль в менталитете любого народа, формируя образ жизни, психические реакции, физическое строение, которые воплощаются в составляющих менталитета. Так, суровый климат России обусловил такие черты россиян как психологическую замкнутость, мужество, сдержанность. Природные условия влияют на глубину и скорость реакций при разных жизненных ситуациях. Так, психологи, изучая количество движения за один час у представителей разных 
национальностей: самые подвижные - мексиканцы (180 движений), самые медлительные - финны (1 движение), а англичане вообще не сделали ни одного движения [5].

Русский менталитет имеет свои особенности. Как отмечал Н. Бердяев, в русской культуре пространство и время становятся средством сплочения людей вокруг родной земли и дома. Русский менталитет своими корнями связан с географическими условиями, поэтому россиян не подавляют огромные пространства и непредсказуемый климат.

Влияние менталитета на творческие ресурсы русских людей заключается в таком национальном характере как трудолюбие, способность терпеливо, кропотливо выполнять работу, стремление делать всё добросовестно и своими руками, благоразумие. Эти черты дают пространство для деловой направленности, ограничивая то, что этому мешает. Непредсказуемые природные и социальные условия способствуют искать выходы из них, что стимулирует творческую активность русского человека, умение нетрадиционно, по-новому, решать проблемы.

Особенно важным элементом национального самосознания является национальная идея, которая выступают его основанием, стержнем, что направляет развитие нации, концентрируясь в национальной идеологии [9].

Большую роль в активизации творческих проявлений менталитета играют социально-культурные факторы, так как они способны определить не только сущность, но и формы жизнедеятельности народа, а также уровень и степень развития творческого потенциала. Социально-культурные факторы обуславливают создание, существование и воспроизводство духовных ценностей, духовного бытия, концентрируясь в духовной культуре народа и нации. Творческий потенциал человека - необъемлемая часть национальной культуры, так как культура «живёт» и проявляет себя в творчестве. Национальная культура пронизывает все «этажи» (уровни) творческого потенциала (телесные, психологические, интеллектуальные, побудительно-мотивационные, с одной стороны, а также виртуальные, эссенциальные, трансцендентальные - с другой) [11]. Творческий потенциал человека в значительной степени взращён мен- тальными особенностями национальной культуры. Национальное развитие любого народа вплетено в более общие исторические процессы. С развитием цивилизации происходят глубинные изменения в обществе. Это, прежде всего, связано с процессом урбанизации - повышении роли города и уменьшение значения села в развитии общества. Процесс урбанизации болезненно сказывается на сельских жителях, которые, по своей сути, и являются реальными носителями традиционных черт национальной культуры и ментальности. Городская среда денационализирует людей, усредняя их, порождая в массовых масштабах маргинальность, основанную на оторванности людей от привычной культурной среды, от исторических национально-ментальных корней [3].

Маргинал имеет двойственную природу: он несёт в себе одновременно и разрушительные и творческие тенденции, обеспечивая избавление от старых традиций и создание новых духовных ценностей. Теоретическое осмысление традиций и современности в формировании национального самосознания и её ядра - национальной идеи - осуществляет национальная интеллигенция, большая часть которой составляет маргинализированные защитники национальной культуры. Сегодня, на переломных этапах истории, именно национальная интеллектуальная элита (интеллигенция) должна ответить на вопросы, что в ментальных традициях навсегда потеряно, а что ещё можно возродить, что использовать для дальнейшего развития нации.

Сегодня ментальные черты приобретают новые формы существования: наряду с традиционной ментальностью формируются новые искусственные идеологические конструкции - искусственная мифологизация культурно-ментального пространства, романтизация традиций, которые этого не заслуживают, превращая национальную жизнь в национальную утопию (типа коммунизма). Нормальный ход развития нации - это укоренение положительных черт ментальности и возрождение национального самосознания и жизнедеятельности отдельных представителей нации. Если же сосуществование реальной (традиционной) ментальности и её рационально-осознанных форм ведут к разрыву связей между ними, то, в конце концов, такие условия могут привести к затуханию творческих сил нации [11].

\section{ЛИТЕРАТУРА}

1. Абрамов Д. Новый и Третий Рим: Византийские мотивы России / Д. Абрамов, Д. Климентьев. М.: Алгоритм, 2015. 399 с.

2. Бердяев Н. Самопознание: учение Бердяева с комментариями. М.: АСТ, 2018. 319 с.

3. Бобер Ж. Маргинальность в социокультурной системе. СПб.: Политех-Пресс, 2019. 340 с.

4. Войтов А.Г. Менталитет: идеи, идеальное, идеология, идеократия, идейность: монография. 3-е изд., перераб. М.: Дашков и Кㅇ, 2019. 391 с.

5. Клизовский А.И. Основы миропонимания новой эпохи: М.: Эксмо, 2011.877 с.

6. Леонтьев А.Н. Деятельность. Сознание. Личность. М.: Смысл, 2005. 431 с. 
7. Лосский Н.О. История русской философии. СПб.: Азбука-Аттикус, 2018. 603с.

8. Лосский Н.0. Характер русского народа. М.: Посев, 1957. - 151с.

9. Национальная идея России: монография / Б.А. Аникин, 0.Б. Аникин, В.В. Ефимова и др. 2-е изд., перераб. и доп. М.: Дашков и К , 2019.324 с.

10. Некрасова Н.А. Духовность: сущность и проявление: монография / Н.А. Некрасова, С.И. Некрасов. М.: Полиграф сервис, 2014. 139 с.

11. Чаплыгин А.К. Моя Сковородиана: монография. Харьков: Лидер 2015. 282 с.

(c) Некрасов Андрей Сергеевич (sinekrasov@mail.ru).

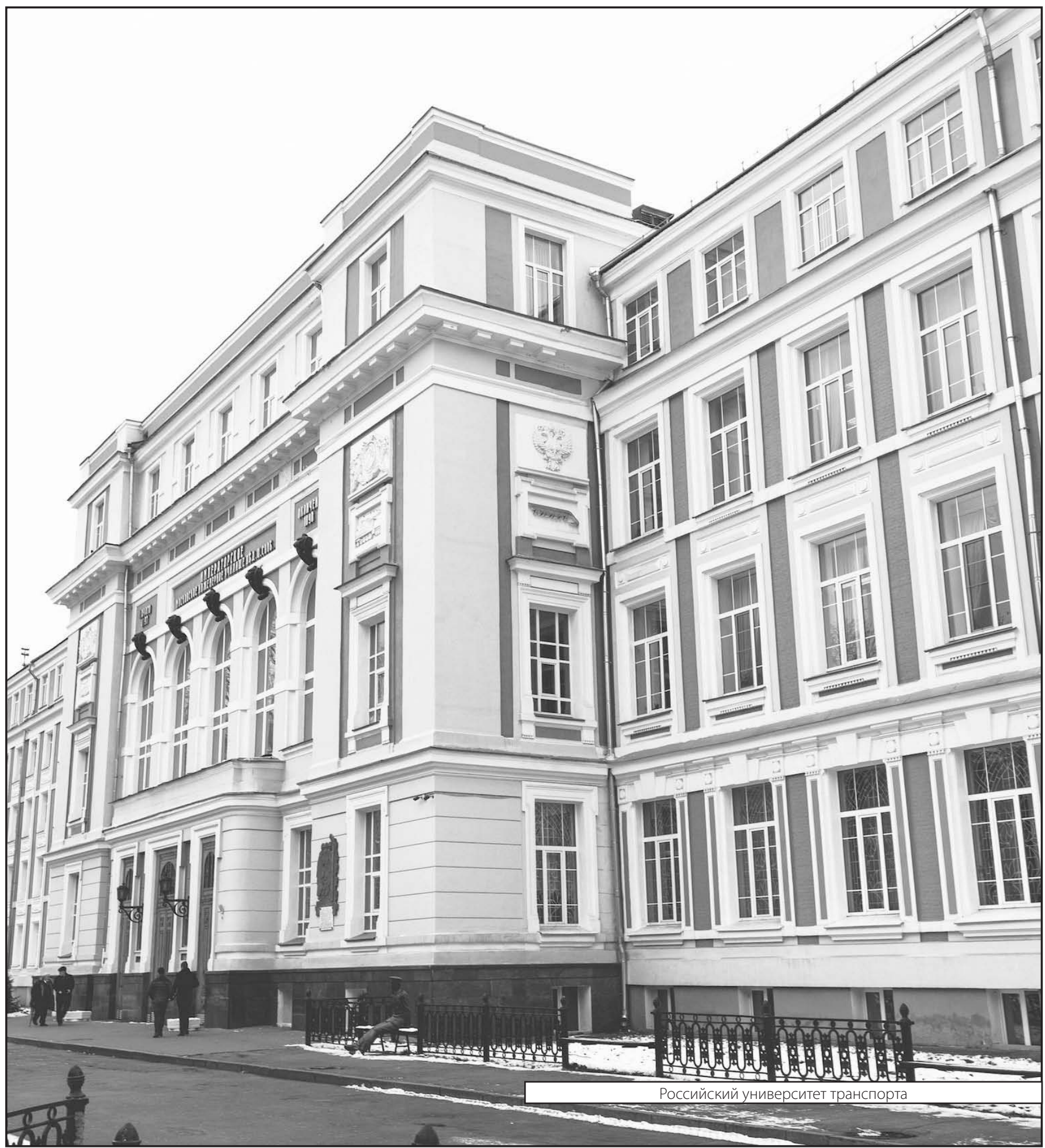

